\title{
Female poverty and intrahousehold inequality in transition economies
}

\section{An unequal distribution of resources within the family is a special concern for female poverty}

Keywords: female poverty, intrahousehold inequality, gender gaps, transition

\section{ELEVATOR PITCH}

Transition to a market economy is accompanied by a period of greater economic uncertainty. Women are likely to suffer substantial disadvantages from this uncertainty compared to men as they are, for example, more likely to lose their job. This not only implies a monetary loss for the entire family, but also degrades female bargaining power within the household, possibly further aggravating their well-being. When intra-household inequality-an unequal distribution of resources among family members-exists, female poverty might be significantly larger than what can be deduced using standard household based poverty measures.

\section{KEY FINDINGS}

\section{Pros}

- More-educated women have more bargaining power, implying a larger share of household resources.

( ) Women with more bargaining power tend to spend more on girls' education, thereby improving future female empowerment.

$\oplus$ Before transition, women's labor and educational outcomes were high in former socialist countries, suggesting an egalitarian position between men and women within families.

๑ Smaller gender pay gaps and broad female participation in the labor market can reduce intrahousehold inequality as well as female poverty.

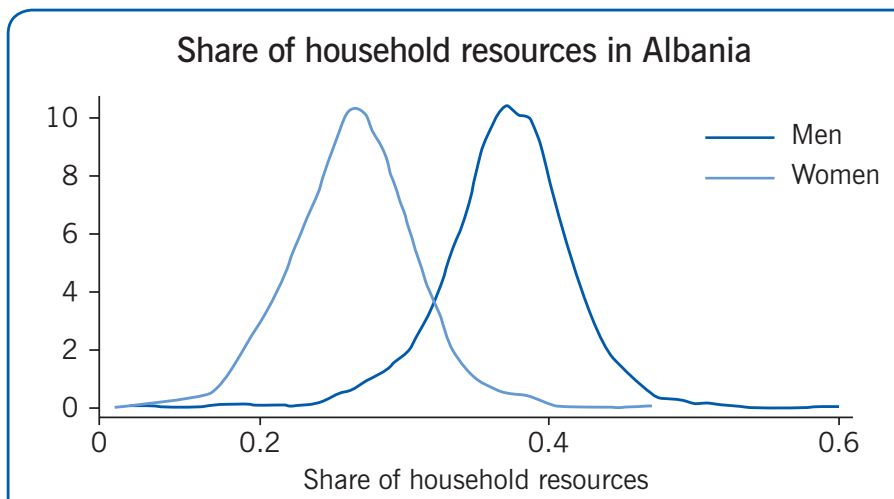

Source: Author's calculations based on a subsample of households with at least one man, one woman, and one child from the Albanian Living Standard Measurement Survey 2002 and the intrahousehold inequality measure computed in [1].

I Z A Zor A of tabor

\section{Cons}

- During transition, women were more likely to lose their jobs, which worsened both families' economic situation and women's relative position within the family.

- Budget constraints and the emergence of high unemployment rates induced major changes to family policy in transition countries, discouraging female labor market participation.

- Intrahousehold inequality can be substantial and growing during transition; this means that female poverty may be much greater than official poverty figures based on household-level data.

\section{AUTHOR'S MAIN MESSAGE}

Evidence shows that women's wages and education relative to men's play key roles in driving intrahousehold inequality. Improving women's education and labor market performances will have multiple positive impacts on female poverty. Policy options include the creation of scholarships to promote female participation into STEM (science, technology, engineering, and mathematics) higher education programs, providing fiscal incentives to firms that hire women in managerial positions, implementing individual income tax schedules in place of family based ones, and providing easier access to childcare facilities. 


\section{MOTIVATION}

Female poverty has been extensively studied in the US and EU. Consistent empirical findings show that the average risk of poverty is generally higher for women in most countries. Single mothers and female immigrants are particularly vulnerable, but the problem is not limited to them. Standard measures of female poverty, however, suffer an important methodological shortcoming: they are based on the unitary model of the household. A key assumption of this model is equal sharing of resources within the household-an assumption that has been widely rejected by numerous empirical studies [2]. This misleading assumption results in female poverty being seriously underestimated [3].

By contrast, non-unitary models of the household, particularly collective models [4], explicitly consider the bargaining process of household members and the resulting distribution of household resources. Recent empirical findings based on these models suggest that intrahousehold inequality is more severe than previously thought and especially relevant during a country's transition process to a market economy, as women may have more trouble both entering and remaining in the labor market than men during such periods of economic uncertainty [1], [5].

\section{Unitary and non-unitary models of the household}

Unitary models of the household assume that family consumption choices are taken as if the household was a single individual who maximizes family utility per a family budget constraint. For this to be the case, either individual preferences must converge into some agreed family preferences (and this process remains unexplained), or the head of the household should behave as a "benevolent dictator" (which holds only under very restrictive assumptions). Furthermore, the incomes of all household members must be fully pooled. Such a model has been widely criticized because it neglects interactions among household members in taking economic decisions and has thus been rejected in the empirical literature (Browning et al., 2014).

Non-unitary models of the household, on the other hand, view the household as a group of individuals, each of whom possesses a relative level of bargaining power when it comes to decision making. This implies that the household decision process can be analyzed under a gender perspective. It is common to analyze households composed of two decision makers (spouses), with possibly different preferences, but it is also possible to consider children as part to the decision process.

Typically, non-unitary models need additional assumptions to identify the distribution of resources within the household. For instance, collective models (a class of nonunitary models) require either assumption on the similarity of preferences for differently composed households, or the observability of individual consumption of at least one commodity and one variable that influences the distribution of resources, but not the consumption preference, often called a "distribution factor."

Source: Browning, M., P.-A. Chiappori, and Y. Weiss. Economics of the Family. New York: Cambridge University Press, 2014. 


\section{DISCUSSION OF PROS AND CONS}

\section{Female poverty and the transition process}

The "feminization of poverty" became a popular issue in the 1990s. Since then, there has been substantial consensus about some particularly vulnerable groups, including single mothers and female immigrants, and the main causes of female poverty. Perhaps the most relevant source of gendered poverty involves discrimination in the labor market, both in terms of employment opportunities and pay. Social and cultural exclusions represent other important forms of gender poverty. For several decades now it has been recognized that research should focus more on the distribution of resources within the household [3], an aspect that is still disregarded in standard measurements of female poverty.

\section{Female poverty measurement, intrahousehold inequality, and time allocation}

How to properly measure poverty remains an open question. There are no simple solutions for addressing the shortcomings of traditional measures of poverty, which are mostly based on household income (or consumption). While one of the more widely discussed aspects is the inadequacy of using only income (consumption) for measuring poverty, another less considered issue is that poverty measures are based on total household income (consumption), which disregards the possibility that some family members may face discrimination within their own household. For example, in patriarchal societies such as India, Turkey, Peru, and others, women traditionally have not had equal access to household resources.

The theoretical model underpinning these traditional poverty measures, the unitary model of the household, assumes that resources are equally shared within the household. In such a framework, female poverty measures may be obtained either by analyzing the gender composition of poor households-though poverty is still defined at the household level-or by analyzing female-headed households. Both approaches are unsatisfactory: they neglect the possibility that household resources may be distributed unevenly, and the latter also implies a selection issue because women may be household heads by necessity (e.g. death of husband, migration, divorce, or abandonment), or as the result of a choice that may not necessary reflect a dominant bargaining position within the household.

The unitary model has been consistently rejected both theoretically and empirically on numerous occasions since the 1980s, and has since been proceeded by the gradual development of alternative household models such as non-unitary models. These newer methods recognize that household behavior is the result of interactions among its members and that the distribution of resources within the household might be unequal. Given a certain set of assumptions, collective models (a class of non-unitary models) can accurately determine how resources are distributed within the household. This knowledge is fundamental to obtain better measures of female poverty and to give policy indications about which channels could be more successfully exploited to reduce intrahousehold inequality and, consequently, female poverty.

Furthermore, collective models can measure resource shares that account for each family member's allocation of time (e.g. labor, home work, caring, and leisure time). This makes it possible to build an extended income concept that accounts for unpaid contributions to the household's well-being and to compute resource shares that include the value of leisure time. 


\section{Female poverty related to labor market conditions}

One of the most recognized causes of female poverty is discrimination in the labor market. Women earn less than men due to the gender pay gap and because of difficulties reconciling domestic tasks with labor market work. The gender pay gap has been widely studied over the last 40 years; Eurostat estimates a 16.2\% difference in the gross hourly earnings of males versus females in Europe for 2014. Moreover, women work less than men due to their typically larger share of domestic responsibilities. Defining total work as the sum of market, domestic, and childcare work, women perform more total work than men in most EU countries, in some cases by more than one hour per day, but perform less paid work. The Harmonized European Time Use Survey shows that, on average, women engage in labor market work $37 \%$ less than men, but perform $82 \%$ more domestic work and $154 \%$ more childcare [6].

In transition countries, these issues may be even more relevant because of the dramatic changes in the labor market. For example, the gender pay gap in Russia went through substantial variations during the transition period, especially after the 1998 financial crisis: according to Russia Longitudinal Monitoring Survey (RLMS) data, in 1994-1996 male wages were about $49 \%$ higher than female wages, while in 2000-2002 the pay gap rose to $58 \%$. On the other hand, female labor force participation has been relatively stable at around $65 \%$, while male participation declined from about $81 \%$ to $72 \%$ in 1998 , and recovered in the following years [7]. The time use data available in some rounds of the RLMS show that in 1994 total work (including domestic chores and caring for children and the elderly) was rather balanced, with women working $7.6 \%$ more than men; by contrast, in 2009 women worked almost $30 \%$ more than men. It is worth noting that changes to family policies related to budgetary restrictions brought about by the transition process, such as a substantial reduction in public childcare and preschool provision, further limited women's access to the labor market by forcing them to spend more time on domestic duties.

In addition to the direct effects mentioned above, because the distribution of household resources has been shown to depend heavily on the relative wage of women with respect to their partners, this sharp increase in the wage gap is likely to have substantially increased intrahousehold inequality, thereby worsening overall female well-being.

\section{Migration affects intrahousehold inequality}

Immigrant women constitute a particularly vulnerable category according to the European Commission. For example, Eastern European countries experienced massive female emigration during the transition process and several studies reveal that migrant women experience difficult conditions in their host countries. On the other hand, a growing body of literature is studying the effects that international migration has on the family members left behind, beyond the positive economic impact of remittances. For example, in Western Balkan countries, the high migration levels have mostly been a young male phenomenon. This has resulted in a decreased supply of left-behind women to the labor market due to their increased household and subsistence farming responsibilities [8]; and has also impacted on their children's education. The odds of secondary school dropout increased (similarly related to the above-mentioned responsibilities), especially for daughters [9], which may have long-term negative effects for female poverty via poorer labor market performances.

Migration is also a fundamental issue for the intrahousehold distribution of resources. Because one spouse typically migrates, and because this is more likely to happen 
in extended families (i.e. families that have multiple generations living in the same household), the bargaining equilibria within the household may change substantially. In more patriarchal societies, bargaining power may shift to elder, left-behind males, which may compromise women's well-being. On the other hand, if the bargaining power shifts to the left-behind mother, she is more likely to invest more in her children, especially in their education [10].

\section{Education as a tool to reduce inequality}

In several Western countries women are outperforming men in terms of their educational outcomes. This has been recognized as an important aspect for female poverty reduction, since highly educated women have greater opportunities to increase their social position, find (better) jobs, and generally escape poverty.

Additionally, when women are more educated their bargaining power and their share of resources within the household improve. This occurs independently of labor market outcomes related to educational achievements (such as household pay gap reductions) and affects the poverty levels of mothers and their female offspring.

With respect to transition countries, while the starting point tends to be very good (most socialist countries were characterized by universal higher education, for both men and women), tight public budget constraints have led to sharp reductions in the availability of public higher education. This is particularly relevant for countries characterized by strong patriarchal family values, as girls may be more likely to forego higher education [9].

\section{Evidence of intrahousehold inequality in transition countries}

Empirical studies estimating intrahousehold inequality are rare, especially when it comes to developing and transition countries. Nevertheless, studies on intrahousehold inequality are available for Albania [1] and Russia [5], [7], [11]. The study on Albania makes use of the World Bank's Living Standard Measurement Survey, a rich household survey containing detailed information on most individual and household characteristics useful for welfare analysis, such as income, consumption, work, migration, health, and education. More studies are available for Russia because of the availability of a long panel database (the RLMS data). This data set was specifically designed to monitor the effects of post-transition Russian reforms on the health and welfare of households and individuals.

\section{Consequences of intrahousehold inequality for female poverty}

Before the communist period, Albania was a strongly patriarchal society, where, especially in mountain and rural areas, the social and economic system was governed by the Kanun code, a set of traditional and mostly unwritten laws handed down from generation to generation since the Middle Ages. The Kanun gave males unquestioned authority within the household and society; one of the consequences of the economic uncertainty that followed the fall of communism was a partial regression toward those traditional patriarchal values. At the same time, the household structure changed substantially due to sustained emigration flows, especially of young males.

A recent study for Albania uses a collective demand system for the study of intrahousehold inequality in migrant-sending households [1]. Although the focus of the study is not on female poverty, many conclusions are highly relevant. Figure 1 presents portions of an 
analysis that elaborates on the results presented in this study. The distribution factors used are: parents' education and age differences, proportion of female children, and child work (number of minors with paid work at the community level). It is worth noting that the analysis is based on a subsample of Albanian households with at least one man, one woman, and one child; as such, these poverty measures can differ substantially from official figures for the entire population.

Figure 1. Distribution of resources vs distribution of spending on clothing

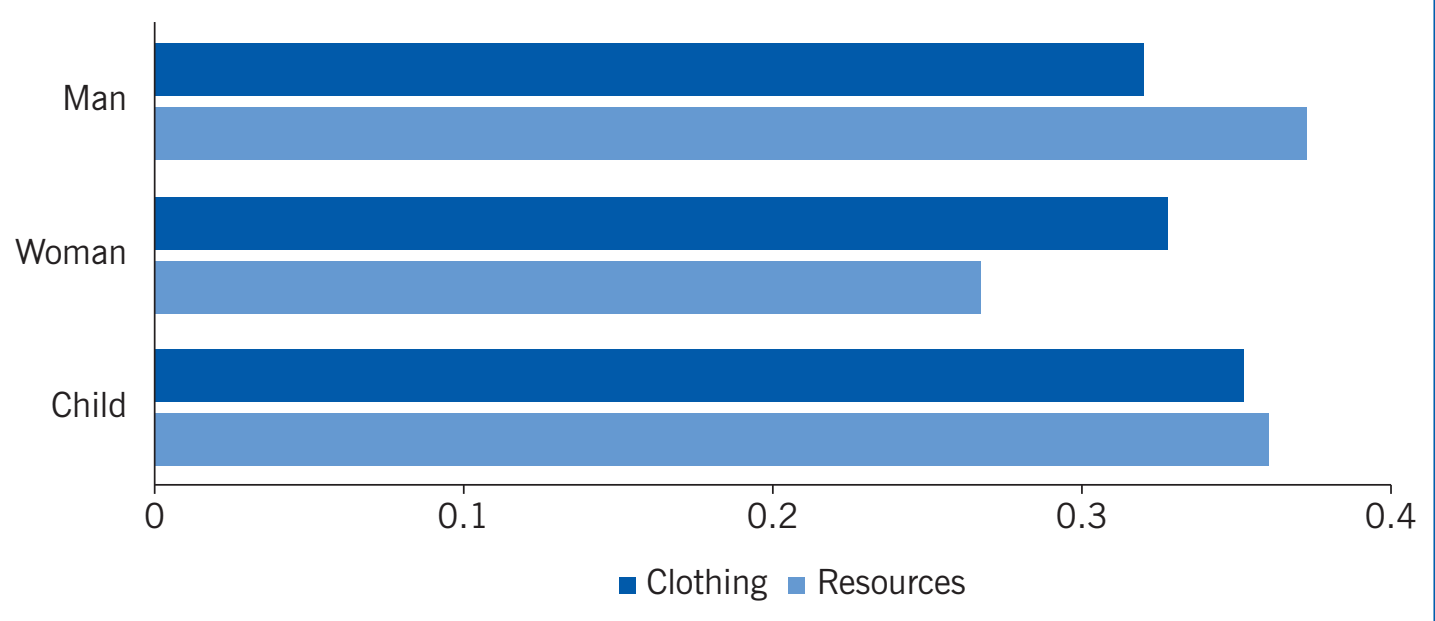

Note: The shares of resources are computed from the intrahousehold inequality measure presented in Mangiavacchi et al. (2014) [1], and represent the average share of consumption for each member of a hypothetical household composed of one man, one woman, and one child. The share of clothing is computed in the same way, but the only source of individual expenditure comes from clothing expenditure as recorded in the data.

Source: Author's own calculations based on the intrahousehold inequality measure computed in Mangiavacchi, L., F. Perali, and L. Piccoli, Intrahousehold Inequality in Migrant-sending Families. ECINEQ Working Paper Series No. 344,2014 [1].

Figure 1 shows that the intrahousehold distribution of resources in Albanian households in 2002 was unfavorable to women, with an average share of $26.7 \%$; almost 11 percentage points less than men. Compared to the distribution of consumption of clothing alone, the use of collective models reveals much higher intrahousehold gender inequality. Indeed, the intrahousehold distribution of clothing consumption is mostly even (slightly favoring children), and one would deduce that intrahousehold inequality does not exist based only on this metric. This raises serious concerns that standard poverty indicators may seriously underestimate female poverty, as shown in Figure 2.

Figure 2 reports two poverty measures, the headcount ratio (the percentage of families/ individuals below the poverty line) and the poverty gap ratio (the average gap between poor families' total expenditure and the poverty line in percentage of the poverty line), computed using the standard methodology and weighting for the number of women within the household. Again, the analysis presents two relevant aspects. First, when weighting for the number of women within the household, all poverty indices are larger. This indicates that women are more likely to live in a poor household, independently of the distribution of resources within the household. Second, when intrahousehold 
Figure 2. General and female poverty measures

\begin{tabular}{lccccc}
\hline & $\begin{array}{c}\text { Headcount ratio } \\
\text { (\% of families below } \\
\text { the poverty line) }\end{array}$ & $\begin{array}{c}\text { Poverty gap ratio } \\
\text { (average gap between } \\
\text { poor families' total } \\
\text { expenditure and } \\
\text { poverty line; \% of the } \\
\text { poverty line) }\end{array}$ & $\begin{array}{c}\text { Poverty line } \\
\text { (60\% of the median } \\
\text { of the scaled monthly } \\
\text { consumption; Albanian } \\
\text { LEK) }\end{array}$ \\
\cline { 2 - 6 } & General & Women & General & Women \\
Equivalence scale & 14.10 & 15.90 & 2.65 & 3.04 & $3,900.0$ \\
\hline $\begin{array}{l}\text { Per-capita } \\
\text { Modified OECD }\end{array}$ & 11.73 & 13.14 & 2.20 & 2.57 & $7,415.6$ \\
$\begin{array}{l}\text { Total expenditure (divided by square } \\
\text { root of household size) } \\
\text { Intrahousehold inequality }\end{array}$ & 12.63 & 12.09 & 2.19 & 2.13 & $8,651.5$ \\
\hline
\end{tabular}

Note: For non-poor, the poverty gap ratio is zero. a. Weighted according to the number of women within each family (e.g. weighted double for a family with two women). b. Weights for household members: head $=1$, additional adult $=$ 0.5 , each child $=0.3$.

Source: Author's own calculations based on the intrahousehold inequality measure computed in Mangiavacchi, L., F. Perali, and L. Piccoli, Intrahousehold Inequality in Migrant-sending Families. ECINEQ Working Paper Series No. 344, 2014 [1].

inequality is accounted for, female poverty indicators are larger: at least $8 \%$ larger for the headcount ratio and at least $28 \%$ larger for the poverty gap ratio. Not only are there noticeably more poor women compared to what standard measures tell, they are also substantially poorer. Such results suggest that intrahousehold inequality might be greater in poor households.

Figure 3. Male and female share of resources by household total expenditure

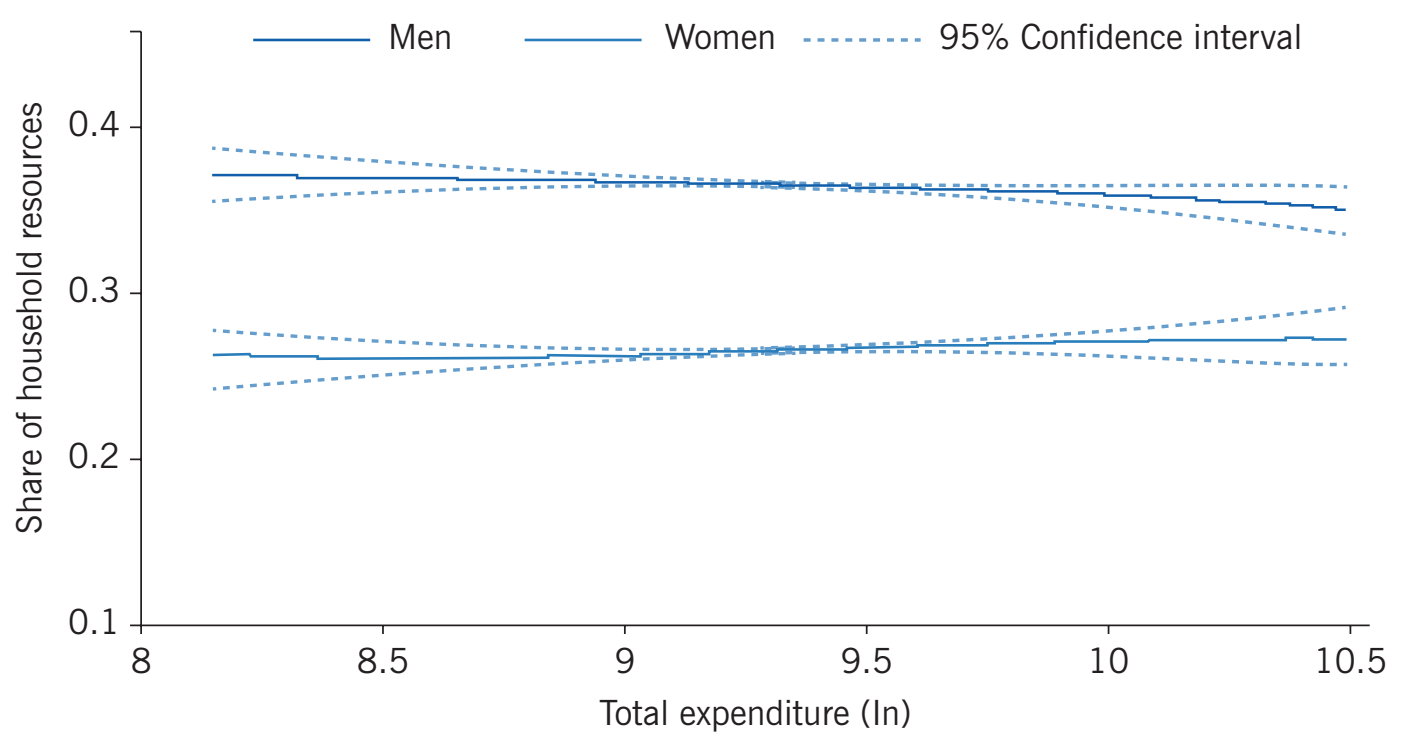

Notes: Computed on a subsample of Albanian households with at least one man, one woman, and one child.

Source: Author's own calculations based on the Albanian Living Standard Measurement Survey 2002 and Mangiavacchi, L., F. Perali, and L. Piccoli, Intrahousehold Inequality in Migrant-sending Families. ECINEQ Working Paper Series No. 344, 2014 [1]. 
Figure 3 plots the share of male and female resources by household total expenditure level (in logarithms). What emerges is that the difference is larger for poor households, but the reduction of intrahousehold inequality with household expenditure is relatively small, indicating that even in rich families there is substantial discrimination against women in terms of resource distribution.

As to the determinants of intrahousehold inequality, results confirm previous findings on the importance of age and educational differences (generally, as women's education and age relative to men increase, so does their share of household resources), and provide novel insights on other aspects, such as the effects of international migration and gender of offspring [1]. First, resources freed up when male migrants leave the household (including remittances) do not significantly improve women's relative position; they seem to be used mostly for children, especially on their education. Second, the proportion of female children is relevant for the distribution of resources: for non-migrant-sending families, having more female children improves men's and children's position (it was not possible to distinguish between daughters and sons in terms of who benefited in this case), and worsens women's position. For migrant-sending families, non-migrant men's relative position (i.e. other men left in the household) is unchanged compared to those in non-migrant-sending families, but women's share of resources reduces by a larger extent, to the advantage of the children's share. It seems that this is driven by women's behavior, possibly because they are more willing to divert part of their resources to their daughters, even at the cost of giving part of those resources to the remaining men in the household. This confirms previous findings that women tend to invest more in children, with education representing the largest share of additional investment.

\section{Russia}

Intrahousehold distribution of resources in Russian households has been studied in a number of articles that focus on income sharing and labor supply [5], [7], [11]. Although these studies do not specifically target female poverty, several results are relevant to the issue.

Intrahousehold inequality estimates for the transition period (1994-1998) suggest that resources were distributed almost equally, with women having access, on average, to $47 \%$ of household resources (children are not accounted for in the analysis), though substantial variability exists [11]. The most important source of heterogeneity comes from intrahousehold gender wage differentials. Households with large wage differentials exhibit greater intrahousehold inequality, while those with small differentials share resources evenly. This evidence suggests that policies aimed at reducing the societal gender pay gap (e.g. equal pay for equal work and promoting female participation in STEM programs) are likely to have a substantial impact on intrahousehold allocation of resources, reducing intrahousehold inequality and, thus, female poverty.

Furthermore, female educational outcomes are relevant: the female share of resources is larger when women have a higher degree of education than men. Thus, if intrahousehold inequality leads to unbalanced educational opportunities in favor of male children, then a long-term negative impact could exist on female poverty. For example, RLMS data show that from 1994 to 1998 the proportion of young higher education graduates (23-29 years old) reduced more for women (from $24.5 \%$ to $16.3 \%$ ) than for men (from $17.3 \%$ to $11.9 \%)$. 
An interesting note about intrahousehold inequality in Russia regards its evolution after the 1998 financial crisis. In the pre-crisis period, relative wages were falling, with male wages falling more sharply than female wages, implying a reduction in the gender pay gap. In the post-crisis period, however, male wages grew much more than female wages, increasing the pay gap up to and above the pre-crisis period. Male and female labor market participation rates followed a similar pattern. The intrahousehold distribution of resources has been shown to respond to gender wage differentials in a stronger way after the financial crisis than before, as if the behavior of husbands and wives changed during the 2000-2004 growth period. Because the wage differential between husbands and wives has been more important for intrahousehold inequality since the financial crisis, larger intrahousehold wage differentials may mean that female poverty reduction has been less pronounced than what is suggested by positive overall trends observed at the household level during the growth period.

\section{LIMITATIONS AND GAPS}

Empirical applications of collective models are still scarce, especially in transition and developing countries. This is primarily due to the high data requirements and statistical skills required to run these models. Furthermore, collective models have only recently developed to the point at which they can accurately determine individual poverty measures (such as female poverty) [12]. Previous specifications could not properly account for the (partially) public nature of some consumption goods, that is, their consumption is not exclusive of a single individual, such as rent, utilities, travel, and so on. However, the data requirements needed to account for public goods are very high and few databases exist that can satisfy them. Statistical institutes and international organization should invest in this type of data collection, allowing more transition countries to benefit from proper individual measures of poverty and inequality.

\section{SUMMARY AND POLICY ADVICE}

The literature shows that measuring inequality across individuals without considering the allocation of resources within households is unreliable. Moreover, recent empirical evidence suggests that intrahousehold inequality is an especially prominent issue in transition countries, incurring a direct impact on female poverty. As such, policymakers must account for intrahousehold inequality when designing anti-poverty programs and targeted benefits (e.g. to women and children).

More specifically, wage and education gender differentials are strong determinants of intrahousehold inequality. While the situation worldwide has improved substantially in recent years, with girls outperforming boys in most educational outcomes, policymakers could further increase the still limited participation of women in STEM areas. Jobs in these fields are generally characterized by better wages, and thus have the potential to improve women's bargaining power within the household. This should be part of the current effort to eliminate the gender pay gap and discrimination.

Women's labor outcomes would also benefit by improving the supply of childcare, which has been substantially reduced due to budget constraints in transition countries. Stronger controls and incentives against job discrimination (with respect to both hiring and pay) are also necessary. Fiscal incentives at household level or favorable taxation schemes for 
gender-balanced firms could be considered. For example, it is recognized that progressive taxation at the individual level, as opposed to joint taxation of couples, provides greater incentives for women's labor force participation. It could even be useful to think about a gender difference in tax progressivity to compensate for the gender pay gap. These kinds of policy interventions would not only reduce intrahousehold inequality and, by extension, female poverty, they would also reduce overall poverty rates by increasing total household resources.

Finally, increasing women's bargaining power will lead to long-term benefits for societies; this is because, as women gain more equality in the household, they tend to invest more in their children's education, ensuring improved outcomes for future generations.

\section{Acknowledgments}

The author thanks two anonymous referees and the IZA World of Labor editors for many helpful suggestions on earlier drafts. Financial support from the Spanish government (project n. ECO2015-63727-R) is gratefully acknowledged. Previous work of the author (together with Lucia Mangiavacchi and Federico Perali) contains a larger number of background references for the material presented here and has been used intensively in all major parts of this article [1].

\section{Competing interests}

The IZA World of Labor project is committed to the IZA Guiding Principles of Research Integrity.

The author declares to have observed these principles.

(c) Luca Piccoli 


\section{REFERENCES}

\section{Further reading}

Chiappori, P.-A., and C. Meghir. "Intrahousehold inequality." In: Atkinson, A. B., and F. Bourguignon (eds). Handbook of Income Distribution Volume 2. Amsterdam: Elsevier, 2015; pp. 1369-1418.

Ponthieux, S., and D. Meurs. "Gender inequality." In: Atkinson, A. B., and F. Bourguignon (eds). Handbook of Income Distribution Volume 2. Amsterdam: Elsevier, 2015; pp. 981-1146.

\section{Key References}

[1] Mangiavacchi, L., F. Perali, and L. Piccoli. Intrahousehold Distribution in Migrant-sending Families. ECINEQ Working Paper Series No. 344, 2014

[2] Browning, M., P.-A. Chiappori, and Y. Weiss. Economics of the Family. New York: Cambridge University Press, 2014.

[3] Findlay, J., and R. E. Wright. "Gender, poverty, and the intrahousehold distribution of resources." Review of Income \& Wealth 42:3 (1996): 335-351.

[4] Bourguignon, F., and P.-A. Chiappori. "Collective models of household behavior: An introduction." European Economic Review 36:2-3 (1992): 355-364.

[5] Cherchye, L., B. De Rock, and F. Vermeulen. "Opening the black box of intrahousehold decision making: Theory and nonparametric empirical tests of general collective consumption models." Journal of Political Economy 117:6 (2009): 1074-1104.

[6] Giannelli, G. C., L. Mangiavacchi, and L. Piccoli. "GDP and the value of family caretaking: How much does Europe care?" Applied Economics 44:16 (2012): 2111-2131.

[7] Lacroix, G., and N. Radtchenko. "The changing intra-household resources allocation in Russia.” Journal of Population Economics 24:1 (2011): 85-106.

[8] Giannelli, G. C., L. Mangiavacchi, and L. Piccoli. "Do parents drink their children's welfare? Intra-household allocation of time between market labour, domestic work and child care in Russia." IZA Journal of Labor \& Development 2:1 (2013): 1-23.

[9] Mendola, M., and C. Carletto. "Migration and gender differences in the home labour market: Evidence from Albania.” Labour Economics 19:6 (2012): 870-880.

[10] Giannelli, G. C., and L. Mangiavacchi. "Children's schooling and parental migration: Empirical evidence on the 'left-behind' generation in Albania." LABOUR: Review of Labour Economics and Industrial Relations 24:S1 (2010): 76-92.

[11] Kalugina, E., N. Radtchenko, and C. Sofer. "How do spouses share their full income? Identification of the sharing rule using self-reported income." Review of Income and Wealth 55:2 (2009): 360-391.

[12] Browning, M., P.-A. Chiappori, and A. Lewbel. "Estimating consumption economies of scale, adult equivalence scales, and household bargaining power." Review of Economic Studies 80:4 (2013): 1267-1303.

\section{Online extras}

The full reference list for this article is available from:

http://wol.iza.org/articles/female-poverty-and-intrahousehold-inequality-in-transition-economies

View the evidence map for this article:

http://wol.iza.org/articles/female-poverty-and-intrahousehold-inequality-in-transition-economies/map 